This is the version of the article accepted for publication in Journal of Business Ethics published online by Springer: https://link.springer.com/article/10.1007/s10551-017-3456-z

Accepted version downloaded from SOAS Research Online: http://eprints.soas.ac.uk/23838/

Investigating When and Why Psychological Entitlement Predicts Unethical Pro-

\title{
Organizational Behavior
}

\section{(Allan Lee, Gary Schwarz*, Alexander Newman, \& Alison Legood)}

\begin{abstract}
In this research, we examine the relationship between employee psychological entitlement (PE) and employee willingness to engage in unethical pro-organizational behavior (UPB). We hypothesize that a high level of PE-the belief that one should receive desirable treatment irrespective of whether it is deserved-will increase the prevalence of this particular type of unethical behavior. We argue that, driven by self-interest and the desire to look good in the eyes of others, highly entitled employees may be more willing to engage in UPB when their personal goals are aligned with those of their organizations. Support for this proposition was found in Study 1, which demonstrates that organizational identification accentuates the link between PE and the willingness to engage in UPB. Study 2 builds on these findings by examining a number of mediating variables that shed light on why PE leads to a greater willingness among employees to engage in UPB. Furthermore, we explored the differential effects of PE on UPB compared to counterproductive work behavior (CWB). We found support for our moderated mediation model, which shows that status striving and moral disengagement fully mediate the link between PE and UPB. PE was also linked to CWB, and was fully mediated by perceptions of organizational justice and moral disengagement.
\end{abstract}

* Corresponding author: Gary Schwarz, Senior Lecturer in Public Policy and Management, SOAS University of London, gary.schwarz@soas.ac.uk. 
Keywords: Unethical pro-organizational behavior, psychological entitlement, organizational identification, counterproductive work behavior, status striving, organizational justice, moral disengagement.

Growing research has demonstrated that employees commonly engage in unethical behaviors that are intended to serve the interests of their organization (e.g., destroying incriminating files to protect an organization's reputation; disclosing exaggerated information to the public; Umphress and Bingham 2011). This type of behavior has been referred to as unethical proorganizational behavior (UPB) (Umphress et al. 2010), and it is carried out consciously, in a discretionary manner (i.e., it is neither ordered by a supervisor nor part of a formal job description), and in violation of moral hypernorms (Warren 2003). The intention to benefit an organization distinguishes UPB from many other forms of unethical work behavior, such as counterproductive or deviant behavior, which are performed with the intention of harming one's organization and/or its members (e.g., Spector and Fox 2005).

UPB is an important phenomenon for companies to consider because, in the long term, it may hurt their reputations and expose them to lawsuits (Umphress and Bingham 2011). Due to the seemingly increasing number of high-profile events occuring in the public domain whereby ethical standards have been violated in the interest of organizational benefit, scholars have emphasized the need for a more comprehensive understanding of the antecedents of UPB (Pierce and Aguinis 2015). Research has begun to systematically investigate and theorize about UPB with a particular focus on employee motivations to engage in such behaviors (e.g., Chen et al. 2016; Graham et al. 2015; Kong 2016). However, the research to date has largely focused on the examination of situational and attitudinal antecedents of UPB such as leadership (e.g., Effelsberg et al. 2014; Miao et al. 2013), 
affective commitment, and organizational identification (e.g., Chen et al. 2016; Matherne and Litchfield 2012). As noted by Castille and colleagues (2016), such studies have largely neglected the potential role that dispositional variables play in predicting UPB. Examining the role of individual differences as an antecedent to UPB can provide us with greater insight into why people engage in UPB.

To help address this lacuna, the current research explores whether psychological entitlement (PE), which refers to a relatively stable belief that one should receive desirable treatment irrespective of whether it is deserved (Harvey and Martinko 2009), leads individuals to exhibit a greater willingness to engage in UPB. We argue that individuals who are high in PE are more willing to engage in UPB than individuals showing lower levels of PE because the former are more likely to adopt a cognitive style that allows them to reinterpret their unethical actions as being moral (e.g., De Cremer et al. 2009) and that they have a strong desire to maintain their inflated self-esteem by achieving a high status in their organizations (e.g., Rose and Anastasio 2014). Across two studies, we examine the relationship between PE and UPB to advance knowledge of how individual dispositions influence an individual's willingness to engage in UPB. In doing so, we answer the calls from researchers to explore the antecedents of UPB (Umphress et al. 2010) and to extend its nomological network, which is a crucial development in the evolution of the construct. Furthermore, by controlling for the effects of several situational and leadership predictors, we investigate the incremental predictive validity of PE as an antecedent of UPB over and above the variables that have previously been found to influence UPB.

By focusing on PE as a predictor, we also seek to contribute to a small but growing body of literature on the effects of PE in the workplace. By exploring mediating and moderating mechanisms linking PE with UPB, our study advances this literature by providing a more granular understanding of how PE functions in the workplace. Additionally, in the 
current research we aim to investigate whether the mechanisms linking PE to UPB differ from those that link PE to other forms of unethical behavior, specifically counterproductive work behavior (CWB). While there is some evidence that UPB is empirically distinct from CWB (Umphress et al. 2010), researchers have paid little attention to empirically testing whether the underlying motives for these forms of unethical behavior are distinct. In the current research we argue that UPB is performed with the intention to benefit an organization, whereas CWB is performed with the intention of harming the organization or the individuals within it. We specifically examine three theoretically derived mediating variables: status striving, organizational justice perceptions and moral disengagement. Furthermore, across both of our studies, we test for the potential role of organizational identification as a boundary condition that accentuates the link between PE and UPB.

\section{Literature Review and Hypotheses Development}

\section{Unethical Pro-Organizational Behavior}

UPB is defined as "actions that are intended to promote the effective functioning of the organization or its members and violate core societal values, mores, laws, or standards of proper conduct" (Umphress and Bingham 2011, p. 622). This definition incorporates two components. First, UPB is unethical and violates widely shared norms of ethical behavior and not only the rules established by a particular group. The second component focuses on the intentions of an unethical action. Unlike CWB, which is carried out with the intention of harming one's organization, its members, or both, UPB is conducted with the purpose of benefiting one's organization, its members, or both (Umphress and Bingham 2011). UPB can involve acts of commission (e.g., exaggerating the employing company's achievements) and omission (e.g., not providing relevant information to external stakeholders). 
UPB can have serious consequences because its occurrence may hurt a company's reputation and expose it to lawsuits. For example, the German engineering firm Siemens was required to pay $€ 2.5 \mathrm{bn}$ in fines because its employees had used bribes to secure large-scale contracts (Dietz and Gillespie 2012). The scandal cost the jobs of its CEO, Chairman and all but one of its managing board members. In this case, employees engaged in unethical behavior with the intention of helping the company, as illustrated by the following justification for paying bribes provided by an Italian Siemens manager: "The alternative would have been to turn down the project, which would have denied Siemens not only the business but also a foot in the door in the Italian market" (Dougherty 2007).

UPB is an inherently paradoxical construct. While the behavior is considered to be "unethical" by society, it may be conducted with the best intentions (e.g., for the benefit of the organization) and with moral justifications (e.g., the end justifies the means). This behavior parallels that described in Hannah Arendt's (1945) essay 'Organized Guilt and Universal Responsibility,' in which she analyzes why individuals act irresponsibly and abandon their broader community for the benefit of their in-group. Employees may develop a rigid framing that disregards their distal context (Palazzo et al. 2012) and develop "a moral microcosm that likely could not survive outside the organization" (Brief et al. 2000, p. 484). Hence, morality becomes subordinate to instrumental rationality serving organizational purposes (Bauman 1991).

The empirical investigation of UPB remains in its infancy, with studies beginning to analyze potential antecedents, mediators and boundary conditions (e.g., Effelsberg et al. 2014; Graham et al. 2015). However, such research has largely focused on situational and attitudinal predictors, and there is currently limited evidence of the role of individual characteristics in predicting UPB. Recently, Castille and colleagues (2016) demonstrated that individuals who are high in the "dark" trait of Machiavellianism are more willing to engage 
in UPB.. To further address this gap in the literature and to gain a better understanding of this phenomenon in organizational settings, the present study aims to investigate the role of PE in predicting employee willingness to engage in UPB.

\section{Psychological Entitlement}

$\mathrm{PE}$ is a pervasive sense that one deserves more than others, even if this is not commensurate with one's actual abilities and efforts (Campbell et al. 2004). High levels of PE are positively associated with self-esteem, which is generally defined as individuals' perceptions of their own value (Rosenberg et al. 1995) and the confidence constructs of self-sufficiency and vanity. Entitled individuals care deeply about what others think, they are attuned to the thoughts of others, and they desire to be close to them (Rose and Anastasio 2014). Such characteristics are predictable with well-documented linkages between entitlement and Narcissistic Personality Disorder (e.g., Wink 1991). However, recent work has distinguished between the two concepts by showing that narcissism is primarily about the self, whereas entitlement is about the self in relation to others (Rose and Anastasio 2014). In a workplace setting, PE has been linked to several undesirable outcomes (e.g., Harvey and Martinko 2009). However, empirical work that investigates the influence of entitlement on unethical behavior in the workplace remains very limited (see Harvey and Dasborough 2015).

\section{Psychological Entitlement and Unethical Pro-Organizational Behavior}

$\mathrm{PE}$ is associated with a tendency to behave in unethical and counterproductive ways in the workplace, such as abusing co-workers (e.g., Harvey and Harris 2010). In the current research, we contend that high levels of PE will also increase one's willingness to engage in UPB. Crucially, we propose that the underlying reasons for highly entitled individuals to be more willing to engage in UPB differ from the reasons of their engagement in other forms of unethical or counterproductive work behavior. Specifically, we argue that highly entitled 
Unethical Pro-Organizational Behavior and Psychological Entitlement

employees have underlying psychological motives that predispose them to be willing to engage in UPB.

One reason why individuals high in PE may engage in UPB is related to status concerns. Specifically, such individuals hold a consistently positive view of themselves (Snow et al. 2001), and they have a desire to maintain this positive self-image. They also have a deep concern for what others think of them, and they place great value on receiving approval and recognition from others (Rose and Anastasio 2014). Highly entitled individuals have been shown to be motivated to pursue self-serving goals while having limited concern for how such goals are achieved (Bishop and Lane 2002). Accordingly, we argue that highly entitled individuals wish to achieve a high level of status within an organization, and to be viewed as high-performers by others and that they will be willing to take shortcuts to get there. As such, while UPB reflects behavior that strives to meet the goals of the organization, it likely also reflects self-interest in that personal goals may coincide with organizational goals (Effelsberg et al. 2014). Thus, we argue that highly entitled employees may be more willing to engage in UPB from a desire to achieve high status. Hence, such employees may resort to UPB as an ego defense mechanism (Brown and Starkey 2000), which allows them to maintain and protect their inflated self-concept.

Furthermore, research has demonstrated that psychologically entitled individuals are disposed to attributional biases that allow them to reinterpret their immoral actions as being, in fact, moral (e.g., Tsang 2002) through a process known as moral rationalization. De Cremer and colleagues (2009) suggest that entitlement may encourage individuals to morally rationalize unethical decision making (e.g., the unfair allocation of resources) to justify their actions. As Harvey and Martinko (2009) observed, PE is associated with a tendency to blame others for negative outcomes. We argue that the tendency of those high in PE to make biased 
attributions and rationalize unethical behavior will lead such individuals to morally disengage (e.g., Bandura, 1999) while making decisions. This leads us to:

Hypothesis 1 Psychological entitlement will be positively associated with unethical proorganizational behavior.

\section{PE and UPB: The Moderating Role of Organizational Identification}

Social identity theory posits that part of a person's self-concept is derived from group membership (Tajfel 1978). When employees identify with their organization, the organization's identity becomes tied to their self-definition (Albert et al. 2000). Umphress and colleagues (2011) noted that as organizational identification becomes stronger, employees may be tempted to disregard ethical principles to help their organization. Because entitlement is also positively related to self-esteem (Campbell et al. 2004) and to high expectations of reward, it can be expected that those who are high in entitlement will also want to be viewed as high performers. It follows, therefore, that the link between entitlement and UPB should be stronger when entitled individuals' personal goals coincide with organizational goals. In the current research, we argue that employees who identify closely with their organization and at the same time are high in PE are most willing to engage in UPB. This leads us to:

Hypothesis 2 The positive association between psychological entitlement and unethical pro-organizational behavior will be stronger for employees with higher organizational identification than those with lower organizational identification.

\section{Study 1}

The aims of this field study are threefold. First, we provide an initial test of the effects of PE on employee willingness to engage in UPB. Second, we explore how the effects of PE on employee willingness to engage in UPB compares with the effects of various situational and 
attitudinal antecedents, specifically affective organizational commitment, transformational leadership, and leader-member exchange (LMX). Third, we investigate whether organizational identification moderates the link between PE and followers' willingness to engage in UPB.

\section{Method}

Sample and Procedure

We collected data from a Chinese textile manufacturing company with revenues of more than one billion RMB that is located in Zhejiang Province. Questionnaires were distributed to two sources (supervisors and their immediate subordinates) across two time periods in early and late April 2014 to minimize common method variance (Podsakoff et al. 2012). The questionnaires were translated from English into Chinese by bilingual members of the research team following a back-translation procedure (Brislin 1993). All of the participants were informed that their answers are confidential. At time 1, the data on PE, perceptions of transformational leadership, and demographic variables (age and gender) were collected. At time 2, two weeks later, the participants were asked to rate UPB, affective organizational commitment, organizational identification, and LMX. In addition, the data on subordinate performance were collected from their immediate supervisors to be used as a control (Schwarz et al. 2016). On average, each supervisor rated 10.5 subordinates. The average age of the subordinates was 29.30 years, $75 \%$ were male, and they had an average organizational tenure of three years. In total, 252 responses were received, which represents a response rate of $88.42 \%$.

Measures

For all of the multiple-item scales in this study, the participants rated each item using a 5point Likert scale where $1=$ strongly disagree and $5=$ strongly agree.

Study variables 
PE was measured using the nine-item entitlement measure developed by Campbell and colleagues (2004) $(\alpha=.94)$. An example item is "I honestly feel I'm just more deserving than others". The six-item scale developed by Umphress and colleagues (2010) was used to measure employee willingness to engage in UPB $(\alpha=.90)$. An example item is "If it would help my organization, I would exaggerate the truth about my company's products or services to customers or clients". Organizational identification was measured using Mael and Ashforth's (1992) six-item scale $(\alpha=.81)$. An example item is “My organization's successes are my successes".

\section{Control variables}

One of the aims of this study is to establish whether PE has a unique effect on UPB, above the effects that have been found in previous studies. Accordingly, we measured a number of variables to control for factors that have previously been associated with UPB. Specifically, we measured affective commitment, which reflects an employee's emotional attachment to his or her organization (Meyer et al. 1993), using the six-item scale that was developed by Meyer and colleagues (1993) $(\alpha=.78)$. An example item is "I feel personally attached to my work organization". Matherne and Litchfield (2012) demonstrated that individuals with high levels of affective organizational commitment are more likely to engage in UPB. Similarly, previous research has suggested that both transformational leadership and LMX quality can influence followers to be more willing to engage in UPB (Effelsberg et al. 2014). Accordingly, we controlled for the role of transformational leadership using the sevenitem scale developed by Carless and colleagues (2000) $(\alpha=.85)$. An example item is "my supervisor gives encouragement and recognition to staff". LMX quality was measured using the seven-item measure (LMX7) developed by Graen and Uhl-Bien (1995) that has been used in the Chinese context before (e.g., Newman et al. 2015) $(\alpha=.79)$. An example item is "My supervisor recognizes my potential". Supervisor ratings of performance were also controlled 
for in the analysis using a 3-item scale taken from Heilman and colleagues (1992), as employees who do not meet their performance requirements may be more likely to engage in unethical behavior to improve their performance $(\alpha=.82)$. Additionally, we included a number of demographic variables, including age, gender and organizational tenure as previous research has indicated that such variables may be related to unethical behavior (e.g., Kish-Gephart et al. 2010) and, importantly, UPB (e.g., Kalshoven et al. 2016).

\section{Results}

Table 1 reports the item intercorrelations, internal consistency reliabilities, and descriptive statistics for all independent, control and dependent variables that were used in Study 1. As predicted, PE was positively associated with UPB, which provides initial support for Hypothesis 1. Furthermore, compared with the other predictor variables, PE had the highest correlation $(\mathrm{r}=.74)$ with UPB. The correlation indicates that PE has a large association with willingness to engage in UPB (Cohen 1992). In comparison, organizational identification had a moderate correlation $(r=.28)$. In line with previous research, the leadership variables transformational leadership and LMX also showed a significant correlation with UPB $(\mathrm{r}=.30$ and .49 , respectively).

\section{$\underline{\text { Insert Table } 1 \text { About Here }}$}

\section{Discriminant Validity}

Given the high correlation between PE and UPB, it is important to demonstrate that the two variables are distinct. To do so, a series of confirmatory factor analyses (CFAs) were conducted using LISREL 8.80 to establish discriminant validity between the multi-item variables that were self-rated by employees within this study (see Table 2).

\section{$\underline{\text { Insert Table } 2 \text { About Here }}$}

The goodness-of-fit of a six-factor model that included all of the employee-rated variables (PE, UPB, transformational leadership, LMX, affective commitment and 
organizational identification) was acceptable $\left(X^{2}=1272.35\right.$, df $=764$, RMSEA $=0.05$, IFI $=$ 0.90, CFI $=0.90)$. The fit of the six-factor model was then compared to a series of five-factor models in which the variables were combined, and a one-factor model in which all of the items were loaded onto one factor. In all cases, the goodness-of-fit statistics of these models were significantly worse than those of the six-factor model, which suggests adequate discriminant validity between study variables.

\section{Hypothesis Testing}

Because the participants in this study consisted of individuals nested within teams $(\mathrm{N}=24$ teams) there was the potential that uncorrected tests of individual-level relationships may have inadvertently contained team level effects (e.g., Bauer et al. 2006). To assess this possibility, we calculated the ICC(1), which indexes the amount of variance in a given variable that can be attributed to group membership. We found the ICC(1) value of .63 for UPB to be high (Bliese 1998), indicating that a large portion of the variance in the ratings of employee UPB could be accounted for by team membership. Therefore, our data required a statistical approach that not only accounts for its hierarchical or nested nature but also for potential dependency in the Level 1 (individual-level) data. Accordingly, we tested our hypotheses by using a multi-level model, which included but the individual (employee) level and the team level (see Table 3).

We tested the random coefficient models using multilevel regression analysis; employing SPSS (Version 23) software and using its mixed analysis function. To test the moderating effect of organizational identification, organizational identification and PE were both grand mean centered and multiplied together. This interaction term was included in the model specified above along with the various control variables. In the first step, we tested a null model in order to examine the percentage of variance in residing at each of the two levels (individual and team). Specifically, in Model A, an empty model was calculated allowing the 
intercept to vary across both individual and group levels. In Model B, we entered our control variables. We then entered the standardized (mean centered) predictor variable (PE), moderator variable (organizational identification) before computing the interaction term, and entered this in Models $\mathrm{C}, \mathrm{D}$, and E respectively. The results of each model are shown in Table 3, and they provide support for Hypothesis 1, showing that PE had a significant relationship with UPB $(\beta=.43, \mathrm{t}(217)=6.95 \mathrm{p}<.01$; Model D).

\section{Insert Table 3 About Here}

Table 3 shows some additional interesting findings. Of all the variables that were included that have previously been linked to willingness to engage in UPB, only LMX ( $\beta=$ $.28, \mathrm{t}(221)=2.66 \mathrm{p}<.01)$ was significantly associated with willingness to engage in UPB once all of the variables had been entered into the regression equation. Conversely, affective organizational commitment, organizational identification and transformational leadership had no significant association with willingness to engage in UPB.

Hypothesis 2 predicted that organizational identification would moderate the relationship between PE and willingness to engage in UPB. Specifically, we argued that higher levels of organizational identification would accentuate the effects of PE. As seen in Table 3, the interactive effect of PE and organizational identification on willingness to engage in UPB is significant $(\beta=.23, t(238)=2.64, p<.01)$. To facilitate interpretation (see Figure 1), we plotted the simple slopes for two values of organizational identification (with 1 standard deviation (SD) below the mean indicating lower levels of identification and $1 \mathrm{SD}$ above the mean indicating high levels of identification), as recommended by Aiken and West (1991). In line with our hypothesis, Figure 1 shows a stronger positive slope at higher levels of organizational identification $(\beta=.63, t(103)=7.56, p<.01)$ compared with lower levels $(\beta=.33, t(223)=4.07, p<.01)$. In other words, support was found for a moderation effect of 
Unethical Pro-Organizational Behavior and Psychological Entitlement

organizational identification. Specifically, high levels accentuated the positive effects of PE on willingness to engage in UPB.

\section{$\underline{\text { Insert Figure } 1 \text { About Here }}$}

\section{Study 1 Discussion}

The findings of Study 1 provide initial support for Hypothesis 1 by revealing significant positive associations between PE and an employee's willingness to engage in UPB. Support was also found for the role of organizational identification in moderating this relationship. This supports Hypothesis 2, which posits that the link between the two will be stronger when an entitled individual's personal goals coincide with organizational goals. Importantly, these effects were found when controlling for a number of key variables that have previously been linked to a willingness to engage in UPB (i.e., transformational leadership, affective organizational commitment, and LMX). Taken together, these results suggest a strong link between PE and willingness to engage in UPB.

\section{Study 2 Hypotheses Development}

Study 2 aims to build on the results of Study 1 in several ways. First, we explore the relationship between PE and UPB in a different context to determine whether the direct and moderating effects found in Study 1 are replicable in a different setting. This is critical to prove the robustness of the findings and to show that they are generalizable to other organizational and cultural contexts. Accordingly, Study 2 uses a sample that is based in the United Kingdom. Second, we extend the model tested in Study 1 to include an additional dependent variable, CWB, to explore the differential effects of PE on both UPB and CWB. In doing so, we aim to show that UPB is distinct from CWB. Furthermore, in examining several mediators in Study 2, we aim to elucidate the underlying mechanisms that explain why individuals who are high in PE are more willing to engage in both UPB and CWB. 


\section{Counterproductive Work Behavior and Unethical Pro-Organizational Behavior}

Both UPB and CWB are forms of unethical behavior; which refers to behavior that violates core societal values, mores, laws, or standards of proper conduct (Donaldson and Dunfee 1994). It is possible that individuals may believe that benefiting their organizations may also benefit themselves (Umphress et al. 2010). Therefore, UPB is not divorced from the selfinterested motives of unethical behavior. However, from a conceptual perspective, UPB and CWB are distinct in the sense that the former is carried out with the intention of benefitting an organization, whereas the latter is carried out with the intention of harming it (e.g., Bennett and Robinson 2000). In reality, both may ultimately harm the organization, but importantly the motives behind each type of behavior differ, at least from a theoretical perspective.

Umphress and colleagues (2010) provided initial support for a distinction between UPB and CWB by highlighting a moderate correlation between the two variables $(\mathrm{r}=.41)$ and by showing discriminant validity between the two constructs through a CFA. However, subsequent research has largely ignored the differences between the two variables, with researchers tending to focus on UPB in isolation from other forms of unethical behavior and vice versa. Thus, the literature has not explored whether different mechanisms explain why individuals are willing to engage in UPB compared to CWB. This is an important step in the evolution of the UPB construct as it would expand its nomological network and provide stronger evidence for the differences between UPB and CWB. Furthermore, antecedents that have been found to predict UPB may also predict CWB, and thus it is vital to empirically determine whether the mechanisms that link PE to both UPB and CWB differ. In prior work, Castille and colleagues (2016) found that the trait of Machiavellianism predicts UPB. As research has also demonstrated theoretical and empirical links between Machiavellianism and CWB (Greenbaum et al. 2014), it is therefore impossible to determine whether those high in 
this trait are willing to engage in UPB and CWB for the same or different reasons. The same is true of $\mathrm{PE}$, which has also been linked to different forms of $\mathrm{CWB}$, such as workplace conflict (Harvey and Martinko 2009), co-worker abuse (Harvey and Harris 2010), and abusive supervision (Whitman et al. 2013). The aforementioned findings suggest that in addition to predicting UPB, PE is also likely to predict levels of CWB. This leads us to:

Hypothesis 3 Psychological entitlement will be positively associated to counterproductive work behavior.

\section{Psychological Entitlement and Unethical Behavior: Underlying Mechanisms}

\section{Status Striving}

In Study 1, we argued that highly entitled employees tend to be more willing to engage in UPB in part due to a desire to maintain and enhance their inflated self-concept and, importantly, to be viewed by others as high-performers. Thus, a willingness to engage in UPB represents an ego defense mechanism (Brown and Starkey 2000) that serves as a short cut to personal goals that may, on the surface, be seen to benefit the organization. To test this explanatory mechanism, we explore status striving as an underlying mechanism that links PE to UPB. Status striving represents an agentic interpersonal motive (Hogan 1996). Whereas communal motives compel people to connect with others, agentic motives drive individuals to exert interpersonal influence and to try to secure power and dominance within a hierarchy (Barrick et al. 2002). PE has theoretical links with status striving, as entitlement leads individuals to seek to maintain an enhanced status vis-à-vis others (e.g., Campbell et al. 2004) as discussed in Study 1.

Prior work indicates a link between a desire for status and UPB (Castille et al. 2016). This link has been attributed to the fact that those who are high in the desire for status pursue their own self-interests at the expense of others and the organizations that they are affiliated 
with (e.g., Dahling et al. 2009). While status striving has conceptual links with UPB, we do not expect to find a positive relationship between status striving and CWB. As CWB reflects actions performed with the intention of harming an organization (or the individuals within it), it would not be advantageous for individuals who strive for high status to engage in behavior that goes against organizational norms and that could be negatively perceived by other members of the organization if detected. In other words, deliberately engaging in CWB bears the risk of having a negative effect on an individual's status in an organization even though some CWB is done secretively. This leads us to:

Hypothesis 4 Status striving will mediate the positive relationship between psychological entitlement and unethical pro-organizational behavior.

\section{Organizational Justice Perceptions}

The preceding hypothesis focuses on explaining the relationship between PE and UPB. An additional aim of Study 2 is to explore variables that may differentially explain the link between PE and CWB. Specifically, we argue that perceptions of organizational justice are central for understanding this link. Their inflated sense of self means that entitled people typically experience outcomes such as anxiety and dissatisfaction with workplace policies, outcomes, and rewards (Miles et al., 1989). As such, it is likely that PE will be negatively associated with perceptions of organizational justice. Most justice research accepts that (at least) three distinct justice types exist: distributive, procedural, and interactional (e.g., Cropanzano et al. 2001) and in the current research we argue that PE will be negatively related to all three dimensions. Entitled employees are generally less likely to perceive organizational justice for two related reasons. Firstly, they have a tendency to hold very high opinions of themselves, and secondly, they have exceedingly high demands and expectations at work (e.g., Campbell et al. 2004). These tendencies are likely to result in entitled 
employees perceiving a disproportionally large discrepancy between what they feel they are owed and what they actually receive in return from the organization (Exline et al. 2004). According to Adams' (1965) equity theory, when one's outcome-to-input ratio is not equivalent to the ratio of a comparitive person, feelings of relative deprivation will result. Such feelings are likely to have a negative impact on organizational justice perceptions in the workplace (e.g., Zoogah 2010). This is particularly relevant to issues of distributive justice. However, we argue that the perceptions of unfairness will extend to other forms of justice, namely procedural and interpersonal justice, which reflect the perceived fairness of decisionmaking processes and interpersonal treatment respectively. For instance, entitlement is highly interpersonal, emphasizing one's assumptions about how others should treat the self. PE implies that a person expects special, preferential treatment from others (Exline et al. 2004). As such special treatment is not always forthcoming, those who are high in PE are less likely to perceive interpersonal fairness.

Interestingly, early discussions related to PE drew connections between entitlement and justice and commented on how entitlement affects our views of justice (e.g., Deutsch 1985) However, as recently noted by Jordan and colleagues (2016), the relationship between PE and organizational justice perceptions has yet to be empirically explored. As we argue that PE will be negatively associated with multiple aspects of organizational justice, we focus on overall justice perceptions. More recently, it has been suggested that overall justice is the proximal driver of outcomes, with each of the above-mentioned specific justice types playing a more distal role (e.g., Ambrose and Schminke 2009)

Previous research has demonstrated that organizational justice perceptions predict CWB (see meta-analysis by Dalal 2005). This work drew on the aforementioned equity perspective (Adams 1965), which suggests that an individual who perceives inequity or injustice will attempt to restore balance by engaging in retaliatory behaviors such as CWB 
(e.g., Spector and Fox 2005). Thus, we argue that organizational justice perceptions will mediate the link between PE and CWB. Put simply, those high in PE are less likely to perceive organizational justice, which in turn will lead to CWB as a form of retaliation. Conversely, we do not predict that perceptions of justice will predict the willingness to engage in UPB. As UPB is a pro-organizational behavior, in accordance with social exchange theory (Umphress and Bingham 2011), perceptions of injustice should make employees be less inclined to engage in such behavior. This leads us to:

Hypothesis 5 Perceptions of organizational justice will mediate the positive relationship between psychological entitlement and counterproductive work behavior.

\section{Moral Disengagement}

The final mediating variable that we explore in Study 2 is moral disengagement, which is the deactivation of moral self-regulatory processes through the use of several interrelated cognitive mechanisms (e.g., Bandura 1999). Moral disengagement explains the enactment of unethical or deviant behavior through self-regulation and in particular the ability to inhibit or override motivational tendencies (Schmeichel and Baumeister 2004). Empirical evidence shows that moral disengagement plays a significant role in the explanation of various forms of unethical behavior at work (e.g., Barsky 2011; Moore et al. 2012). Furthermore, studies have found that certain personality traits predict one's tendency to morally disengage (e.g., Egan et al. 2015).

In the present study we argue that PE is associated with a cognitive style that is likely to increase tendencies to morally disengage. Specifically, research has demonstrated that those high in PE have skewed attributions and a lower need for cognition compared to those low in PE (Harvey and Martinko 2009). As such, those high in PE tend to have attribution styles that reinforce favorable self-perceptions by emphasizing self-serving explanations for 
workplace outcomes. This finding has conceptual links to moral disengagement, which involves the use of similar cognitive distortions to reinterpret immoral acts as being justifiable. Thus, we argue that the tendency of those high in PE to evaluate the world in a biased way will enable such individuals to easily disengage from potential moral quandaries that arise in the workplace. For example, entitled individuals take credit for positive outcomes, and they blame others for negative events while overlooking contradictory information (Harvey and Martinko 2009). Similarly, moral disengagement involves the attribution of blame for unethical behavior away from oneself and placing fault with the target of the harmful behavior (e.g., Bandura 1986). Moreover, PE is associated with a need for power and dominance and with ambition, greed, hostility, and toughness (Campbell et al. 2004), all of which make the moral justification of unethical acts easier to reconcile.

Taken together, we posit that the attributional style and selfishness associated with PE will lead entitled individual to morally disengage. Higher levels of moral disengagement should in turn predict both UPB and CWB. Empirical research has found that moral disengagement has a positive association with a range of CWBs (e.g., Moore et al. 2012). Furthermore, strong theoretical links between moral disengagement and UPB have been proposed (Umphress and Bingham 2011). Chen and colleagues (2016) for instance demonstrated that moral disengagement is associated with UPB, arguing that when employees face moral dilemmas in which the organization's interests are at stake, moral disengagement eliminates self-deterrents to harmful behavior and encourages self-approval of unethical conduct. Thus, based on theoretical and empirical support, we argue that moral disengagement will mediate the links between PE and both CWB and UPB. This leads us to:

Hypothesis 6a Moral disengagement will mediate the positive relationship between psychological entitlement and unethical pro-organizational behavior. 
Unethical Pro-Organizational Behavior and Psychological Entitlement

Hypothesis 6b Moral disengagement will mediate the positive relationship between psychological entitlement and counterproductive work behavior.

\section{The Moderating Role of Organizational Identification}

Through Study 1, we demonstrated that the link between PE and UPB is accentuated by organizational identification. In the present study, we further explore this moderation effect and extend it to explore moderated mediation. Specifically, we argue that organizational identification will moderate the hypothesized links between our proposed mediators and UPB. Hypotheses 4 and 5 posit that status striving and moral disengagement will explain the link between PE and UPB. We further suggest the second stage of this mediation pathway will be accentuated by higher levels of organizational identification. As discussed above, status striving reflects an agentic motivation whereby individuals seek power and the pursuit of self-interests (Hogan 1996). Organizational identification leads individuals to experience the organization's interest as self-interest (e.g., Ashforth and Mael 1989). Thus, status striving combined with high organizational identification is likely to create a situation whereby employees will seek to achieve organizational goals that are aligned with their own goals regardless of the cost. This combination is therefore likely to increase willingness to engage in UPB as a mean of achieving high status in the organization..

Highly entitled employees are also more likely to engage in moral disengagement. As discussed above, this tendency renders those who are high in PE susceptible to all forms of unethical behavior. We argue that high levels of organizational identification will serve to direct this susceptibility towards UPB. Put differently, organizational identification motivates individuals to pusure organizational goals. If combined with moral disengagement, then this motivation will likely result in little regard for the morality of the process. Thus, individuals who choose to disregard personal moral standards and who strongly identify with their 
organization are more likely to engage in unethical acts that favor the organization. Based on the above rationale, we propose the following hypotheses:

Hypothesis 7a Organizational identification will moderate the mediated relationship between psychological entitlement and unethical pro-organizational behavior, such that status striving will have a stronger positive effect when organizational identification is high rather than low.

Hypothesis $7 \mathbf{b}$ Organizational identification will moderate the mediated relationship between psychological entitlement and unethical pro-organizational behavior, such that moral disengagement will have a stronger positive effect when organizational identification is high rather than low.

\section{Study 2}

\section{Method}

Sample and Procedure

The sample included 230 adult online panel members (provided by Qualtrics Panel), who reside in the United Kingdom. Participation was voluntary in exchange for cash or gift cards. All of the respondents were working adults, exactly half of whom were female and $74 \%$ were employed full-time. Questionnaires were distributed electronically across two time periods from May through June 2016 to minimize common method variance (Podsakoff et al. 2012). All of the participants were informed that their answers were confidential, and several attentional filters were included to ensure that the participants were paying attention. Each questionnaire was coded with an identification number to allow the researchers to match the responses over time. At time 1, data on PE and LMX were collected. At time 2, one month later, participants were asked to rate their willingness to engage in UPB, CWB, organizational identification, moral disengagement, status striving, and organizational justice. 
Unethical Pro-Organizational Behavior and Psychological Entitlement

\section{Measures}

A number of the measures that were used in Study 2 mirrored those used in Study 1 with the addition of CWB, status striving, perceptions of organizational justice and moral disengagement. PE was measured using the 9-item entitlement measure developed by Campbell and colleagues (2004) $(\alpha=0.91)$. The 6 -item scale developed by Umphress and colleagues (2010) was used to measure employee willingness to engage in UPB ( $\alpha=0.92)$. To measure CWB, we used 15 items from Bennett and Robinson's (2000) workplace deviance measure. Participants were asked how often they had engaged in counterproductive behaviors over the last year (e.g., "Intentionally worked slower than you could have worked"). While all other scales in this study used a 5-point Likert scale $(1=$ strongly disagree and $5=$ strongly agree $)$, responses to these items were made on 7 -point scales $(1=$ never, $7=$ always). As exploratory factor analysis suggested that the 15 items loaded onto three separate factors we decided to treat CWB as a higher order factor comprised of three sub factors. The higher order factor $(\alpha=.80)$ and subscales $(\alpha=.84, \alpha=.83, \alpha=.89)$ exhibited good reliability. Organizational identification was measured using Mael and Ashforth's (1992) 6-item scale $(\alpha=.91)$. Status striving was measured using the 12 items developed by Barrick and colleagues (2002) $(\alpha=.92)$. As an example, one item states "I always try to be the highest performer." Perceptions of organizational justice were measured using the 6-item scale developed by Ambrose and Schminke (2009) ( $\alpha=.91)$. An example item is "Overall, I am treated fairly by my organization." Moral disengagement was assessed using Moore and colleague's (2012) six-item scale ( $\alpha=.87)$, an example item is "Playing dirty is sometimes necessary in order to achieve noble ends." Based on the results of Study 1, we controlled for LMX $(\alpha=.94)$, using the same scale as in Study 1 , as this was found to have a significant effect on UPB when all variables were included in the regression analysis. We also controlled for gender. 
Unethical Pro-Organizational Behavior and Psychological Entitlement

\section{Results}

Table 4 reports the item intercorrelations, internal consistency reliabilities, and descriptive statistics for all of the variables used in Study 2. A number of the correlations shown in this table are notable. As in Study 1, PE is significantly associated with UPB $(r=.26)$, however this correlation is substantially smaller than that found in Study $1(r=.74)$. Thus, across both studies we find significant correlations between PE and UPB, but we also find differences in terms of the magnitude of this correlation. As predicted in Hypothesis 3, PE was also found to positively correlate with $\mathrm{CWB}(\mathrm{r}=.14)$.

\section{$\underline{\text { Insert Table } 4 \text { About Here }}$}

Discriminant Validity

As was the case for Study 1, it was essential to show discriminant validity between the variables measured in our study. In particular, it is vital to distinguish UPB from CWB, given the potential overlap between the two variables. Accordingly, a series of CFAs were conducted using LISREL 8.80 to establish discriminant validity between these variables and between the other multi-item variables examined in this study. As in Study 1, an eight-factor model in which all of the study variables were included as separate latent factors produced a better model fit $\left(\mathrm{X}^{2}=2644.29, \mathrm{df}=1349, \mathrm{RMSEA}=0.065, \mathrm{IFI}=0.86, \mathrm{CFI}=0.86\right)$, compared to any model that combined these latent factors into a model with fewer factors. For instance, a seven-factor model with UPB and CWB combined exhibited a significantly poorer model fit $\left(X^{2}=2932.24, \mathrm{df}=1356, \mathrm{RMSEA}=0.071, \mathrm{IFI}=0.84, \mathrm{CFI}=0.83\right)$.

Hypothesis Testing

Unlike the participants of Study 1, none of the participants of the present study worked together or shared a manager; thus our analysis was conducted at the individual level. Our hypothesized model represents a second stage moderated mediation model. That is, status 
striving, organizational justice perceptions, and moral disengagement were tested as mediators of the relationship between PE and UPB and CWB, with organizational identification examined as a second stage moderator of the path from these mediators to UPB and CWB. To test our moderated mediation model we used Hayes' (2013) PROCESS macro (Model 15) for SPSS (Version 23) to obtain bias-corrected bootstrapped confidence intervals (using 5,000 bootstrap samples) for conditional indirect effects (see Table 5).

\section{$\underline{\text { Insert Table } 5 \text { About Here }}$}

As is shown in Table 5, PE was significantly associated with all of the mediating variables. PE positively predicted status striving $(\beta=.42, \mathrm{SE}=.06, \mathrm{p}<.01)$ and moral disengagement $(\beta=.37, \mathrm{SE}=.07, \mathrm{p}<.01)$, and was negatively associated with perceptions of organizational justice $(\beta=-.17, \mathrm{SE}=.06, \mathrm{p}<.01)$. In turn, these mediating variables had differential effects on UPB compared to CWB. In line with Hypothesis 4, status striving predicted an individual's willingness to engage in UPB $(\beta=.28, \mathrm{SE}=.07, \mathrm{p}<.01)$ but not CWB $(\beta=-.04, \mathrm{SE}=.08$, n.s.). Support for the mediating role of status striving in the link between PE and UPB is seen in Table 6, which shows the estimates and bias-corrected bootstrapped $95 \%$ confidence intervals for the conditional indirect effects. The conditional indirect effects of PE on UPB through status striving were significant at all levels of the moderator (organizational identification), as indicated by the fact that the $95 \%$ CI did not pass through zero. Thus, support was found for Hypothesis 4.

\section{$\underline{\text { Insert Table } 6 \text { About Here }}$}

As predicted in Hypothesis 5, we found that organizational justice perceptions mediate the link between PE and CWB. Justice perceptions predicted CWB $(\beta=-.28, \mathrm{SE}=$ $.08, \mathrm{p}<.01)$, but not one's willingness to engage in UPB $(\beta=.01, \mathrm{SE}=.07$, n.s. $)$. Support for an indirect effect between PE and CWB was found as the 95\% CI did not include zero (see Table 6). We also found support for the moderating effect of organizational identification on 
the link between organizational justice and CWB. A significant interaction effect was found $(\beta=-.11, \mathrm{SE}=.05, \mathrm{p}<.05)$, and the conditional indirect effects shown in Table 6 indicate a larger indirect effect at higher moderator values. Thus, the conditional indirect effect of PE on CWB was more significant when organizational identification was high.

The final mediating variable examined was moral disengagement. Hypothesis 6 predicted that moral disengagement would mediate the link between PE and both UPB and CWB. Again, initial support for this hypothesis was found as moral disengagement had a significant relationship with $\mathrm{UPB}(\beta=.33, \mathrm{SE}=.06, \mathrm{p}<.01)$ and $\mathrm{CWB}(\beta=.66, \mathrm{SE}=.07, \mathrm{p}$ $<.01)$ as shown in Table 5. Evidence of a significant indirect effect is shown in Table 6; indicating that moral disengagement mediates the relationship between PE and both UPB and CWB. We also found support for a moderating effect of organizational identification in the link between moral disengagement and UPB. A marginally significant interaction effect was found $(\beta=.10, \mathrm{SE}=.06, \mathrm{p}<.10)$ with the conditional indirect effects as shown in Table 6 , indicating a larger indirect effect at higher moderator levels. Thus, the conditional indirect effects of PE on UPB were more significant when organizational identification was high. This relationship is shown graphically in Figure 2.

\section{Insert Figure 2 About Here}

It should also be noted that PE did not have a direct effect on either UPB $(\beta=.06, \mathrm{SE}$ $=.07$, n.s. $)$ or $\mathrm{CWB}(\beta=-.08, \mathrm{SE}=.08$, n.s. $)$ in our model when mediators were included, indicating that the aforementioned variables fully mediated the link between PE and UPB. Furthermore, organizational identification did not moderate the direct effect between PE and UPB.

\section{Study 2 Discussion}


The results of Study 2 support our hypotheses regarding the mediating roles of status striving, moral disengagement, and perceptions of organizational justice. Specifically, both status striving and moral disengagement were found to mediate the link between PE and UPB. In relation to $\mathrm{CWB}$, both moral disengagement and perception of organizational justice were found to mediate the PE-CWB link. We also found support for organizational identification as modertator of the effects of these mediators on UPB and CWB. In particular, organizational identificantion attenutaed the effects of moral disengagement on UPB; although this effect was only marginally significant. However, we did not find support for organizational identification accentuating the effects of status striving on UPB. We did however find that higher levels of identification with the organization made perceptions of injustice more powerful and increased the changes of retaliation in the form of CWB. Low justice perceptions may signal greater violation of expectations when employees identify more strongly with the organization. For instance, research has demonstrated that high identifiers expect their own group to be more fair and just than low identifiers, and if this is not the case, they exhibit higher levels of disappointment (De Cremer 2006). Accordingly, in the aforementioned research, injustice led to acts of retaliation, but mainly so when collective identification was high rather than low. Our findings are in line with this by demonstrating that organizational identification exacerbates the relationship between justice perceptions and CWB.

\section{General Discussion}

Together, the results of our two studies address three principal aims. First, we sought to test whether PE has a significant impact on employee willingness to engage in UPB beyond previously investigated antecedents. Second, we investigated the role of organizational identification in accentuating the relationship between PE and UPB. Third, we sought to 
explore the various theoretically driven mechanisms that could explain the effects of PE on both UPB and CWB. The results found are largely consistent across both studies in support of a positive link between PE and UPB and the moderating role of organizational identification. In addition, from Study 2 we found evidence that status striving and moral disengagement are the underlying mechanisms that explain the PE-UPB link.

\section{Theoretical Implications}

Overall, a number of distinct empirical and theoretical contributions arise from the present research. With regard to UPB, our findings contribute to the growing literature on the potentially unethical nature of various pro-organizational behaviors. As such, we advance understanding of how individual dispositions influence the willingness of individuals to engage in UPB and in doing so answer the calls from researchers to explore the antecedents of UPB (Umphress et al. 2010). Additionally, by identifying PE as an antecedent of UPB, our findings contribute to the knowledge of the role of PE in the workplace. Previous studies have explored the effects of entitlement on ill-intentioned unethical behaviors, such as coworker abuse and conflict with supervisors (Harvey and Harris 2010; Harvey and Martinko 2009). The present research is unique in its examination of a distinct form of unethical behavior, one that is engaged in with the intention of benefitting an organization (UPB) and in the process oneself. In doing so, we inform the PE literature by identifying distinct pathways that explain the effects on UPB and CWB.

The primary contribution of our research is the extension of the nomological network of UPB. Since its first measurement and empirical tests (Umphress et al. 2010), scant research has explored the role of individual differences in predicting UPB or the underlying processes that explain such relationships. However, our research demonstrates that personality characteristics, in this case PE, can explain significant variance in employee 
willingness to engage in UPB. Thus, we build on recent work (e.g., Castille et al. 2016), by exploring how individual characteristics can influence this important outcome. Furthermore, we show the underlying motivations for highly entitled employees' willingness to engage in UPB as opposed to CWB. Investigating such mediating pathways is essential as it can help to explain the intentions that lead to this specific form of unethical conduct. In particular, it is vital that research on UPB is able to distinguish this form of unethical behavior from other forms of unethical behavior, such as CWB.

Our findings suggest that the motivations for engaging in UPB show both similarities and differences to the motivations for engaging in CWB. Specifically, we found that that entitled employees have a tendency to be status driven, which in turn leads them to engage in UPB. This finding is interesting for two reasons. First, the fact that status striving predicts UPB and not CWB highlights that different processes can explain the PE-UPB relationship compared to the PE-CWB relationship. To our knowledge, this is the first study that demonstrates distinct underlying processes that explain why individuals engage in UPB and CWB. Second, this finding to some extent challenges conventional theorizing regarding the underlying motives that may explain UPB. Research has typically argued that the primary intention of UPB is to benefit an organization, its members, or both (e.g., Umphress and Bingham 2011; Chen et al. 2016). Thus, unlike other forms of unethical behavior, which are driven primarily by self-interest (e.g., Kish-Gephart et al. 2010), UPB is often conceptualized as being comparatively selfless, driven by a misguided attempt to serve one's organization and reciprocate favorable treatment (e.g., Umphress and Bingham 2011). In the current research, we posited and found support for the proposition that individuals high in PE will be more willing to engage in UPB to satisfy their own needs for status. Thus, the notion that UPB represents a somewhat virtuous act represents an overly simplistic view of employee motivation. 
Whereas status striving was found to mediate the link between PE and UPB, perceptions of organizational justice were found to mediate the link between PE and CWB. Again, this finding provides support for distinct pathways that can explain an individual's willingness to engage in UPB as opposed to CWB. This finding also represents an important contribution to the understanding of the effects of PE in the workplace. As noted by Harvey and Dasborough (2016, p. 464) "workplace entitlement is a vexing and contemporary issue for modern organizations that has gone largely unstudied thus far." In particular, the reasons why PE often leads to detrimental employee behavior are poorly understood. Given the important role that organizational justice perceptions have on employee behavior, demonstrating the effects of PE on such perceptions constitutes an important step forward in understanding why entitled employees are often a negative force within organizations.

Whereas, status striving and organizational justice perceptions were found to mediate the link between PE and UPB and CWB, moral disengagement emerged as a mediator that explains the link between PE and both UPB and CWB. As predicted, highly entitled individuals exhibited a higher tendency to morally disengage, making them susceptible to both UPB and CWB. These findings further highlight the pitfalls associated with having highly entitled employees in the workplace, supporting recent research linking PE to other primarily undesirable workplace outcomes (Harvey and Harris 2010; Harvey et al. 2014). This finding also highlights potential similarities between UPB and CWB. While we assert that these are distinct constructs, our findings pertaining to moral disengagement suggest that some of the underlying processes that explain UPB also explain CWB. Indeed, moral disengagement has previously been empirically linked to both UPB (e.g., Chen et al. 2016) and CWB (e.g., Moore et al. 2012), albeit not in the same study. Again, this finding suggests that although UPB and CWB are distinct, both theoretically and empirically, they have more in common than scholars have previously suggested. 
As discussed above, the present research tested a number of mediators that could help explain the link between PE and both UPB and CWB. Given that mutiple mediators were included in our model, this raises the questions regarding which of these mediators has a larger effect and thus which is best able to explain the effects of PE on UPB and CWB. The results show that both moral disengagement and status striving had a significant effect on UPB. In relation to $\mathrm{CWB}$, moral disengagement had a stronger indirect effect compared to organizational justice. Taken together, it appears that moral disengagement is an important variable that explains the effects of PE on unethical behavior.

In addition to shedding light on the mechanisms linking PE to both UPB and CWB, our research provides a rare test of the boundary conditions of such effects. The present research examined the moderating role played by organizational identification, with both studies showing evidence of moderating effects. In Study 1, we demonstrated that organizational identification augments the link between PE and individual willingness to engage in UPB. In Study 2, we found that organizational identification (marginally) moderates the link between moral disengagement and UPB. This suggests that individuals who strongly identify with their organizations and who also exhibit a tendency to morally disengage are more likely to neutralize unethical acts to advance their interests. As suggested by Umphress and Bingham (2010), when employees identify strongly with their organizations, global moral standards may be disregarded.

\section{Managerial Implications}

A number of managerial implications arise from the present research. First, given that our findings suggest that psychologically entitled individuals may exhibit a greater willingness to engage in UPB, organizations must ensure that they put mechanisms in place that reduce the likelihood that employees will engage in such behavior given its potential to detrimentally 
influence an organization's reputation. For instance, in selection and performance evaluation procedures, organizations may seek to measure levels of PE among their employees to determine which employees leaders should focus their attention on.

A common thread running through our theorizing is the notion that entitled individuals have a tendency to make self-serving attributions. It has been shown that high levels of PE are associated with a self-serving attribution style (e.g., Harvey and Martinko 2009) and that this increases an individual's likelihood to morally disengage and perceive injustice in the workplace. As such, managerial tactics aimed at decreasing causal ambiguity will reduce the likelihood of the occurrence of these attributions. Such an attributional style is more easily executed in ambiguous situations in which the causes of workplace outcomes are unclear (e.g., Harvey and Dasborough 2015). Practices such as detailed performance-tracking strategies aimed at illuminating individual employees' contributions may inhibit the formation of biased, self-serving attributions. The use of objective data is likely to be especially important in this context. Other tactics might involve the clarification of the relationship between performance and rewards so that inflated expectations are reduced.

\section{Limitations and Suggestions for Future Research}

A main limitation of the present research pertains to the fact that our main variables were collected from a single source. However, in both of the studies conducted, the predictor and criterion variables were collected at different time points, and data on subordinate performance levels were collected as a control variable from their immediate supervisors in Study 1. Moreover, statistical tools were used to determine discriminant validity. Although this does not allow us to completely rule out common method bias, our study design helped us to address such concerns. We also stress that our use of self-reports to capture the outcome variables UPB and CWB was appropriate given that other members of the organization (e.g., 
supervisors) would have been unable to assess these measures accurately (Umphress et al. 2010).

One point of interest of the current research pertains to observed differences in the correlation between PE and UPB found across our two studies. In Study 1, we found a large correlation between these two variables $(\mathrm{r}=.74)$, whereas a small correlation was found in Study $2(\mathrm{r}=.26)$. The two studies differed most in terms of the cultural contexts examined. Study 1 was conducted in China while Study 2 was conducted in the United Kingdom. Thus, the results seem to suggest that the association between PE and UPB is stronger for China than in the United Kingdom. However, it is not apparent why this would be the case and clearly further research would be needed to draw any robust conclusions regarding cultural differences. What is clear is that this difference in correlation size suggests that the link between PE and UPB is influenced by moderators. We found evidence that organizational identification moderates this relationship and other variables may also explain when this relationship occurs to a greater or lesser extent. Organizational climate, for instance, may moderate the link between PE and UPB. For instance, research has demonstrated that perceptions of an ethical work climate have important effects on ethical decision-making in organizations. Climates perceived as emphasizing social responsibility and rules/codes have been found to moderate individual ethical judgment-behavioral intentions relationships such that employees are less willing to engage in questionable practices even when they themselves do not believe such practices to be unethical (Barnett and Vaicys 2000).

It is also interesting to note that in Study 1 we found an $\operatorname{ICC}(1)$ value of .63, which indicates a strong team-level effect. Whereas our research, as well as previous research on the antecedents of UPB have focused on individual-level predictors, team-level factors may also predict UPB occurence. Given our findings, it would be valuable for future studies to explore UPB as a group-level construct and to examine what might influence it at the team level. For 
instance, research has recently investigated pro-group unethical behavior, a concept that has many similarities with UPB (Thau et al. 2015). This research highlights that one motivation for engaging in pro-group unethical behavior is to limit risk of social exclusion from a group. The authors found that perceived risk of exclusion from one's workgroup predict employee engagement in pro-group unethical behaviors when employees exhibit strong needs for inclusion. This threat of exclusion might also motivate UPB. If there is a strong group norm to engage in such behavior, employees may feel the social pressure to engage in UPB, rather than risk exclusion from the group. Research shows, for example, that work groups may develop counter-productive norms (see van Knippenberg 2000) and that this is likely to extend to norms related to UPB.

To explore the effects of PE on UPB, we controlled for several antecedents previously associated with the construct. For instance, in Study 1 we controlled for effects of LMX, affective commitment, and transformational leadership. Such variables have been shown by previous research to predict UPB (e.g., Matherne and Litchfield 2012). However, we did not control for the individual disposition of Machiavellianism, which recent research demonstrated to be a significant predictor of UPB (Castille et al. 2016). We did not control for this variable, as this study was not published by the time we had designed our research. This is an unfortunate limitation given that Machiavellianism and PE have some similarities. For instance, Machiavellianism is considered to be one of the "Dark Triad" personality traits (e.g., Paulhus and Williams 2002). This also includes the trait of narcissism, of which entitlement is considered to be a component. Research suggests that Machiavellianism is significantly and positively correlated with both narcissism $(r=.25$; Paulhus and Williams, 2002) and entitlement $(r=.43$; Miller and Konopaske 2014). Such research also highlights that the two variables are distinct. However, given that both Machiavellianism and entitlement are significantly associated with UPB, it would be prudent for future studies to 
consider the relative predictive validity of both variables to determine if they account for unique variance or UPB. It would also be interesting to determine whether similar mediators account for the effects of both. Castille and colleagues (2016) did not explore mediating variables in their exploration of the link between Machiavellianism and UPB. Thus, future research could explore mediating variables that may be shared between Machiavellianism and PE as well as when they may provide a unique explanatory pathway.

Finally, as we assessed the mediating roles of status striving, organizational justice, and moral disengagement in only one of our studies, further tests of these mediated pathways are needed to add confidence to our findings. Furthermore, the relatively small indirect effects that were found suggest that other variables may further explain the link between PE and UPB (as well as CWB).

\section{Conclusion}

Across two studies that were carried out in vastly different cultural contexts (China and the United Kingdom) we found that individuals with high levels of PE exhibited a greater willingness to engage in unethical behavior that benefits the organization (UPB) than those with low PE levels. Our research also investigated whether the mechanisms linking PE to UPB were different from those that link PE to other types of unethical behavior, such as CWB. We showed that status striving and moral disengagement fully mediate the link between PE and UPB, whereas perceptions of organizational justice and moral disengagement fully mediate the link between PE and CWB. We found evidence that the positive association between PE and UPB was moderated by organizational identification, as entitled employees were more likely to engage in UPB when their personal and organizational goals coincide. Moreover, we uncovered that organizational identification moderated the mediated relationship between PE and UPB as moral disengagement had a 
Unethical Pro-Organizational Behavior and Psychological Entitlement

stronger positive effect on UPB for higher rather than lower levels of organizational identification. Hence, by identifying PE as an antecedent to UPB and by uncovering the constructs that mediate and moderate the UPB-PE relationship, our research extends UPB's nomological network and provides support for its distinctiveness from other types of unethical behavior. 
Unethical Pro-Organizational Behavior and Psychological Entitlement

\section{References}

Adams, J. S. (1965). Inequity in social exchange. In L. Berkowitz (Ed.), Advances in experimental social psychology (Vol. 2, pp. 267-299). New York: Academic Press.

Aiken, L. S., \& West, S. G. (1991). Multiple regression testing and interpreting interactions. Newbury Park, CA: Sage

Albert, S., Ashforth, B. E., \& Dutton, J. E. (2000). Organizational identity and identification: Charting new waters and building new bridges. Academy of Management Review, 25, $13-17$.

Ambrose, M. L., \& Schminke, M. (2009). The role of overall justice judgments in organizational justice research: a test of mediation. Journal of Applied Psychology, 94, 491-500.

Arendt, H. (1994 [1945]). Organized guilt and universal responsibility. In H. Arendt (Ed.), Essays in understanding, 1930-1954: Formation, exile, and totalitarianism, (pp. 121-132). New York: Harcourt Brace.

Ashforth, B. E., \& Mael, F. (1989). Social Identity Theory and the Organization. Academy of Management Review, 14, 20-39.

Bandura A. (1986). Social foundations of thought and action: A social cognitive theory. Englewood Cliffs, NJ: Prentice-Hall.

Bandura, A. (1999). Moral disengagement in the perpetration of inhumanities. Personality and Social Psychology Review, 3,193-209.

Barnett, T., \& Vaicys, C. (2000). The moderating effect of individuals' perceptions of ethical work climate on ethical judgments and behavioral intentions. Journal of Business Ethics, 27, 351-362. 
Unethical Pro-Organizational Behavior and Psychological Entitlement

Barrick, M. R., Stewart, G. L., \& Piotrowski, M. (2002). Personality and job performance: test of the mediating effects of motivation among sales representatives. Journal of Applied Psychology, 87, 43-51.

Barsky, A. (2011). Investigating the effects of moral disengagement and participation on unethical work behavior. Journal of Business Ethics, 104, 59-75.

Bauman, Z. (1991). Modernity and the Holocaust. Ithaca, NY: Cornell University.

Bauer, D. J., Preacher, K. J., \& Gil, K. M. (2006). Conceptualizing and testing random indirect effects and moderated mediation in multilevel models: New procedures and recommendations. Psychological Methods, 11, 142-163.

Bennett, R. J., \& Robinson, S. L. (2000). Development of a measure of workplace deviance. Journal of Applied Psychology, 85, 349-360.

Bishop, J., \& Lane, R. C. (2002). The dynamics and dangers of entitlement. Psychoanalytic Psychology, 19, 739-758.

Bliese, P. D. (1998). Group size, ICC values, and group-level correlations: A simulation. Organizational Research Methods, 1, 355-373.

Brief, A. P., Dietz, J., Cohen, R. R., Pugh, S. D., \& Vaslow, J. B. (2000). Just doing business: Modern racism and obedience to authority as explanations for employment discrimination. Organizational Behavior and Human Decision Processes, 81, 72-97.

Brislin, R. (1993). Understanding culture's influence on behavior. Fort Worth, TX: Harcourt Brace Publishers.

Brown, A. D., \& Starkey, K. (2000). Organizational identity and learning: A psycho-dynamic perspective. Academy of Management Review, 25, 102-120.

Campbell, W. K., Bonacci, A. M., Shelton, J., Exline, J. J., \& Bushman, B. J. (2004). Psychological entitlement: Interpersonal consequences and validation of a self-report measure. Journal of Personality Assessment, 83, 29-45. 
Unethical Pro-Organizational Behavior and Psychological Entitlement

Carless, S. A., Wearing, A. J., \& Mann, L. (2000). A short measure of transformational leadership. Journal of Business and Psychology, 14, 389-405.

Castille, C. M., Bucker, J. M., \& Thoroughgood, C. N. (2016). Prosocial citizens without a moral compass? Examining the relationship between Machiavellianism and unethical pro-organizational behavior. Journal of Business Ethics, forthcoming.

Chen, M., Chen, C. C., \& Sheldon, O. J. (2016). Relaxing moral reasoning to win: How organizational identification relates to unethical pro-organizational behavior. Journal of Applied Psychology, 101, 1082-1096.

Cohen, J. (1992). A power primer. Psychological Bulletin, 112, 155-159.

Cropanzano, R., Byrne, Z. S., Bobocel, D. R., \& Rupp, D. E. (2001). Moral virtues, fairness heuristics, social entities, and other denizens of organizational justice. Journal of Vocational Behavior, 58, 164-209.

Dahling, J. J., Whitaker, B. G., \& Levy, P. E. (2009). The development and validation of a new Machiavellianism scale. Journal of Management, 35, 219-257.

Dalal, R. S. (2005). A meta-analysis of the relationship between organizational citizenship behavior and counterproductive work behavior. Journal of Applied Psychology, 90, $1241-1255$.

De Cremer, D. (2006). Unfair treatment and revenge taking: The roles of collective identification and feelings of disappointment. Group Dynamics: Theory, Research, and Practice, 10, 220-232

De Cremer, D., van Dijk, E., \& Folmer, C. P. R. (2009). Why leaders feel entitled to take more: Feelings of entitlement as a moral rationalization strategy. In D. De Cremer (Ed.), Psychological perspectives on ethical behavior and decision making (pp. 107-119). Charlotte, NC: Information Age Publishing. 
Unethical Pro-Organizational Behavior and Psychological Entitlement

Deutsch, M. (1985). Distributive justice: A social-psychological perspective. New Haven, CT: Yale University Press.

Dietz, G., \& Gillespie, N. (2012). The recovery of trust: Case studies of organizational failures and trust repair. London: Institute of Business Ethics.

Donaldson, T., \& Dunfee, T. W. (1994). Toward a unified conception of business ethics: Integrative social contracts theory. Academy of Management Review, 19, 252-284.

Dougherty, C. (2007). Bribery trial deepens Siemens woes. New York Times, 13 March.

Effelsberg, D., Solga, M., \& Gurt, J. (2014). Transformational leadership and follower's unethical behavior for the benefit of the company: A two-study investigation. Journal of Business Ethics, 120, 81-93.

Egan, V., Hughes, N., \& Palmer, E. J. (2015). Moral disengagement, the dark triad, and unethical consumer attitudes. Personality and Individual Differences, 76, 123-128.

Exline, J. J., Baumeister, R. F., Bushman, B. J., Campbell, W. K., \& Finkel, E. J. (2004). Too proud to let go: Narcissistic entitlement as a barrier to forgiveness. Journal of Personality and Social Psychology, 87, 894-912.

Graen, G. B., \& Uhl-Bien, M . (1995). Relationship-based approach to leadership: Development of leader-member exchange (LMX) theory of leadership over 25 years: Applying a multi-level multi-domain perspective. Leadership Quarterly, 6, 219-247.

Graham, K. A., Ziegert, J. C., \& Capitano, J. (2015). The effect of leadership style, framing, and promotion regulatory focus on unethical pro-organizational behavior. Journal of Business Ethics, 6, 423-436.

Greenbaum, R. L., Hill, A., Mawritz, M. B., \& Quade, M. J. (2014). Employee Machiavellianism to unethical behavior: The role of abusive supervision as a trait activator. Journal of Management, forthcoming. 
Unethical Pro-Organizational Behavior and Psychological Entitlement

Harvey, P., \& Dasborough, M. T. (2015). Entitled to solutions: The need for research on workplace entitlement. Journal of Organizational Behavior, 36, 460-465.

Harvey, P., \& Harris, K. J. (2010). Frustration-based outcomes of entitlement and the influence of supervisor communication. Human Relations, 63, 1639-1660.

Harvey, P., \& Martinko, M. J. (2009). An empirical examination of the role of attributions in PE and its outcomes. Journal of Organizational Behavior, 30, 459-476.

Hayes, A. F. (2013). Introduction to mediation, moderation, and conditional process analysis: A regression-based approach. New York: Guilford Press.

Heilman, M. E., Block, C. J., \& Lucas, J. A. (1992). Presumed incompetent? Stigmatization and affirmative action efforts. Journal of Applied Psychology, 77, 536-544.

Hogan, R. (1996). A socioanalytic perspective on the five-factor model. In J.S. Wiggins (Ed.), The five-factor model of personality (pp. 163-179). New York: Guilford.

Jordan, P. J., Ramsay, S., \& Westerlaken, K. M. (2016). A review of entitlement implications for workplace research. Organizational Psychology Review, forthcoming.

Kalshoven, K., van Dijk, H., \& Boon, C. (2016). Why and when does ethical leadership evoke unethical follower behavior?. Journal of Managerial Psychology, 31, 500-515.

Kish-Gephart, J. J., Harrison, D. A., \& Treviño, L. K. (2010). Bad apples, bad cases, and bad barrels: meta-analytic evidence about sources of unethical decisions at work. Journal of Applied Psychology, 95, 1-31.

Kong, D. T. (2016). The pathway to unethical pro-organizational behavior: Organizational identification as a joint function of work passion and trait mindfulness. Personality and Individual Differences, 93, 86-91.

Mael, F., \& Ashforth, B. E. (1992). Alumni and their alma mater: A partial test of the reformulated model of organizational identification. Journal of Organizational Behavior, 13, 103-123. 
Unethical Pro-Organizational Behavior and Psychological Entitlement

Matherne, C.F. III, \& Litchfield, S.R. (2012). Investigating the relationship between affective commitment and unethical pro-organizational behaviors: The role of moral identity. Journal of Leadership, Accountability and Ethics, 9, 35-46.

Meyer, J. P., Allen, N. J., \& Smith, C. A. (1993). Commitment to organizations and occupations: Extension and test of a three-component conceptualization. Journal of Applied Psychology, 78, 538-555.

Miao, Q., Newman, A., Yu, J., \& Xu, L. (2013). The relationship between ethical leadership and unethical pro-organizational behavior: Linear or curvilinear effects? Journal of Business Ethics, 116, 641-653.

Miles, E. W., Hatfield, J. D., \& Huseman, R. C. (1989). The Equity Sensitivity Construct: Potential Implications For Worker Performance. Journal of Management, 15, 581588.

Miller, B. K., \& Konopaske, R. (2014). Dispositional correlates of perceived work entitlement. Journal of Managerial Psychology, 29, 808-828.

Moore, C., Detert, J. R., Treviño, Baker, V. L., \& Mayer, D. M. (2012). Why employees do bad things: Moral disengagement and unethical organizational behavior. Personnel Psychology, 65, 1-48.

Newman, A., Schwarz, G., Cooper, B., \& Sendjaya, S. (2015). How servant leadership influences organizational citizenship behaviors: The roles of LMX, empowerment and proactive personality. Journal of Business Ethics, doi 10.1007/s10551-015-2827-6. 114.

Palazzo, G., Krings, F., \& Hoffrage, A. (2012). Ethical blindness. Journal of Business Ethics, 109, 323-338. 
Unethical Pro-Organizational Behavior and Psychological Entitlement

Paulhus, D. L., \& Williams, K. M. (2002). The dark triad of personality: Narcissism, Machiavellianism, and psychopathy. Journal of Research in Personality, 36, 556563.

Pierce, J. R., \& Aguinis, H. (2015). Detrimental citizenship behavior: A multilevel framework of antecedents and consequences. Management and Organization Review, 11, S69-S99.

Podsakoff, P. M., MacKenzie, S. B., \& Podsakoff, N. P. (2012). Sources of method bias in social science research and recommendations on how to control it. Annual Review of Psychology, 63, 539-569.

Rose, K. C., \& Anastasio, P. A. (2014). Entitlement is about 'others', narcissism is not: Relations to sociotropic and autonomous interpersonal styles. Personality and Individual Differences, 59, 50-53.

Rosenberg, M., Schooler, C., Schoenbach, C., \& Rosenberg, F. (1995). Global self-esteem and specific self-esteem: Different concepts, different outcomes. American Sociological Review, 60, 141-156.

Schmeichel, B. J., \& Baumeister, R. F. (2004). Self-regulatory strength. In R. F. Baumeister \& K. D. Vohs (Eds.), Handbook of self-regulation: Research, theory, and applications (pp. 84-98). New York: Guilford Press.

Schwarz, G., Newman, A., Cooper, B., \& Eva, N. (2016). Servant leadership behavior and follower job performance: The mediating effect of public service motivation. Public Administration, 94, 1025-1041.

Snow, J. N., Kern, R. M., \& Curlette, W. L. (2001). Identifying personality traits associated with attrition in systematic training for effective parenting groups. The Family Journal: Counseling and Therapy for Couples and Families, 9, 102-108. 
Unethical Pro-Organizational Behavior and Psychological Entitlement

Spector, P. E., \& Fox, S. (2005). A model of counterproductive work behavior. In S. Fox \& P. E. Spector (Eds.), Counterproductive workplace behavior: Investigations of actors and targets (pp. 151-174). Washington, DC: APA

Tajfel, H. (1978). Social categorization, social identity and social comparison. In H. Tajfel (Ed.), Differentiation between social groups: Studies in the social psychology of intergroup relations (pp. 61-76). London: Academic Press.

Thau, S., Derfler-Rozin, R., Pitesa, M., Mitchell, M. S., \& Pillutla, M. M. (2015). Unethical for the sake of the group: Risk of social exclusion and pro-group unethical behavior. Journal of Applied Psychology, 100, 98-113.

Tsang, J. (2002). Moral rationalization and the integration of situational factors and psychological processes in immoral behavior. Review of General Psychology, $6,25-50$.

Umphress, E. E., \& Bingham, J. B. (2011). When employees do bad things for good reasons: Examining unethical pro-organizational behaviors. Organization Science, 22, 621640.

Umphress, E. E., Bingham, J. B., \& Mitchell, M. S. (2010). Unethical behavior in the name of the company: The moderating effect of organizational identification and positive reciprocity beliefs influencing unethical pro-organizational behavior. Journal of Applied Psychology, 95, 769-780.

Van Knippenberg, D. (2000). Work motivation and performance: A social identity perspective. Applied Psychology, 49, 357-371.

Warren, D. E. (2003). Constructive and destructive deviance in organizations. Academy of Management Review, 28, 622-632. 
Unethical Pro-Organizational Behavior and Psychological Entitlement

Whitman, M. V., Halbesleben, J. R. B., \& Shanine, K. K. 2013. Psychological entitlement and abusive supervision: Political skill as a self-regulatory mechanism. Health Care Management Review, 38, 248-257.

Wink, P. (1991). Two faces of narcissism. Journal of Personality and Social Psychology, 61, $590-597$.

Zoogah, D. B. (2010). Why should I be left behind? Employees' perceived relative deprivation and participation in development activities. Journal of Applied psychology, 95, 159-173. 
This is the version of the article accepted for publication in Journal of Business Ethics published online by Springer: https://link.springer.com/article/10.1007/s10551-017-3456-z Accepted version downloaded from SOAS Research Online: http://eprints.soas.ac.uk/23838/

\section{Table 1}

Descriptive Statistics and Correlations for Study 1 Variables

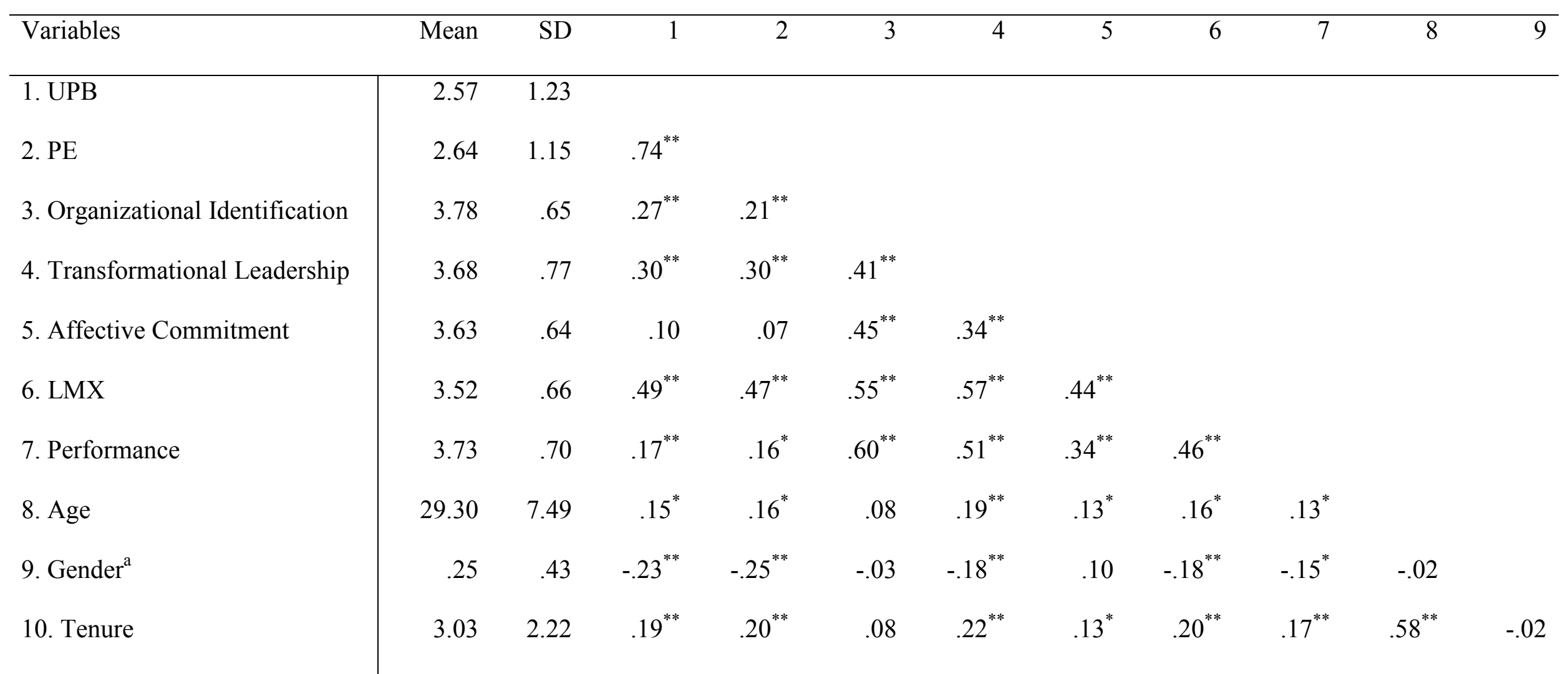

**. Correlation is significant at the 0.01 level (2-tailed). *. Correlation is significant at the 0.05 level (2-tailed).

${ }^{\mathrm{a}} 0=$ Female, $1=$ Male 
This is the version of the article accepted for publication in Journal of Business Ethics published online by Springer: https://link.springer.com/article/10.1007/s10551-017-3456-z

Accepted version downloaded from SOAS Research Online: http://eprints.soas.ac.uk/23838/

Table 2

Study 1 Confirmatory Factor Analyses

\begin{tabular}{llllll}
\hline Model & $\mathbf{X}^{2}$ & $\mathbf{d f}$ & CFI & IFI & RMSEA \\
\hline Six-factor model & 1272.35 & 764 & .90 & .90 & .05 \\
Five-factor model $^{1}$ & 1491.76 & 769 & .86 & .86 & .06 \\
Five-factor model $^{2}$ & 1687.44 & 769 & .82 & .82 & .07 \\
Five-factor model $^{3}$ & 1428.02 & 769 & .87 & .87 & .06 \\
Five-factor model $^{4}$ & 1610.76 & 769 & .84 & .84 & .07 \\
Five-factor model $^{5}$ & 1517.64 & 769 & .86 & .86 & .06 \\
Five-factor model $^{6}$ & 1506.87 & 769 & .86 & .86 & .06 \\
Five-factor model $^{7}$ & 1547.65 & 769 & .85 & .85 & .06 \\
Five-factor model $^{8}$ & 1428.64 & 769 & .87 & .87 & .06 \\
One-factor model $^{2}$ & 3041.14 & 779 & .57 & .57 & .11 \\
\hline
\end{tabular}

Notes. CFI, comparative fit index; IFI, incremental fit index; RMSEA, root mean square error of approximation.

Five-factor model ${ }^{1}$ combines PE and UPB.

Five-factor model ${ }^{2}$ combines UPB and organizational identification.

Five-factor model $^{3}$ combines affective commitment and organizational identification.

Five-factor model ${ }^{4}$ combines affective commitment and transformational leadership.

Five-factor model $^{5}$ combines affective commitment and LMX.

Five-factor model $^{6}$ combines transformational leadership and LMX.

Five-factor model $^{7}$ combines transformational leadership and organizational identification.

Five-factor $\operatorname{model}^{8}$ combines LMX and organizational identification. 


\section{Table 3}

Results of Multilevel Moderation Analysis for UPB, Study 1

\begin{tabular}{|c|c|c|c|c|c|}
\hline Predictor & $\begin{array}{l}\text { Model A } \\
B(S E)\end{array}$ & $\begin{array}{l}\text { Model B } \\
B(S E)\end{array}$ & $\begin{array}{l}\text { Model C } \\
B(S E)\end{array}$ & $\begin{array}{l}\text { Model D } \\
B(S E)\end{array}$ & $\begin{array}{l}\text { Model E } \\
B(S E)\end{array}$ \\
\hline Intercept & $2.43(.19)^{* *}$ & $2.47(.50)^{* *}$ & $2.22(.44)^{* *}$ & $2.62(.53)^{* *}$ & $2.51(.52)^{* *}$ \\
\hline Gender $^{\mathrm{a}}$ & & $.08(.13)$ & $.08(.12)$ & $.10(.12)$ & $.12(.12)$ \\
\hline Tenure & & $.00(.03)$ & $.01(.03)$ & $.01(.03)$ & $.01(.03)$ \\
\hline Transformational Leadership & & $-.15(.08)$ & $-.11(.08)$ & $-.10(.08)$ & $-.07(.08)$ \\
\hline Performance & & $-.14(.08)$ & $-.08(.08)$ & $-.14(.09)$ & $-.14(.09)$ \\
\hline Psychological Entitlement & & & $.43(.06)^{* *}$ & $.43(.06)^{* *}$ & $.49(.06)^{* *}$ \\
\hline Organizational Identification & & & & $.15(.10)$ & $.28(.11)^{*}$ \\
\hline PE X OI & & & & & $.24(.09)^{* *}$ \\
\hline \multicolumn{6}{|l|}{ Random Coefficients } \\
\hline Between Group Variation & $.84(.26)^{* *}$ & $.76(.24)^{* *}$ & $.28(.12)^{* *}$ & $.27(.12)^{*}$ & $.15(.09)$ \\
\hline
\end{tabular}

**. Correlation is significant at the 0.01 level (2-tailed). *. Correlation is significant at the 0.05 level (2-tailed).

Analysis $=$ Maximum Liklihood

${ }^{\mathrm{a}} 0=$ Female, 1 = Male $\mathrm{b}-$ The likelihood ratio tests are constructed by taking the differences of the -2 Log likelihoods of two nested models 


\section{Table 4}

Descriptive Statistics and Correlations for Study 2 Variables

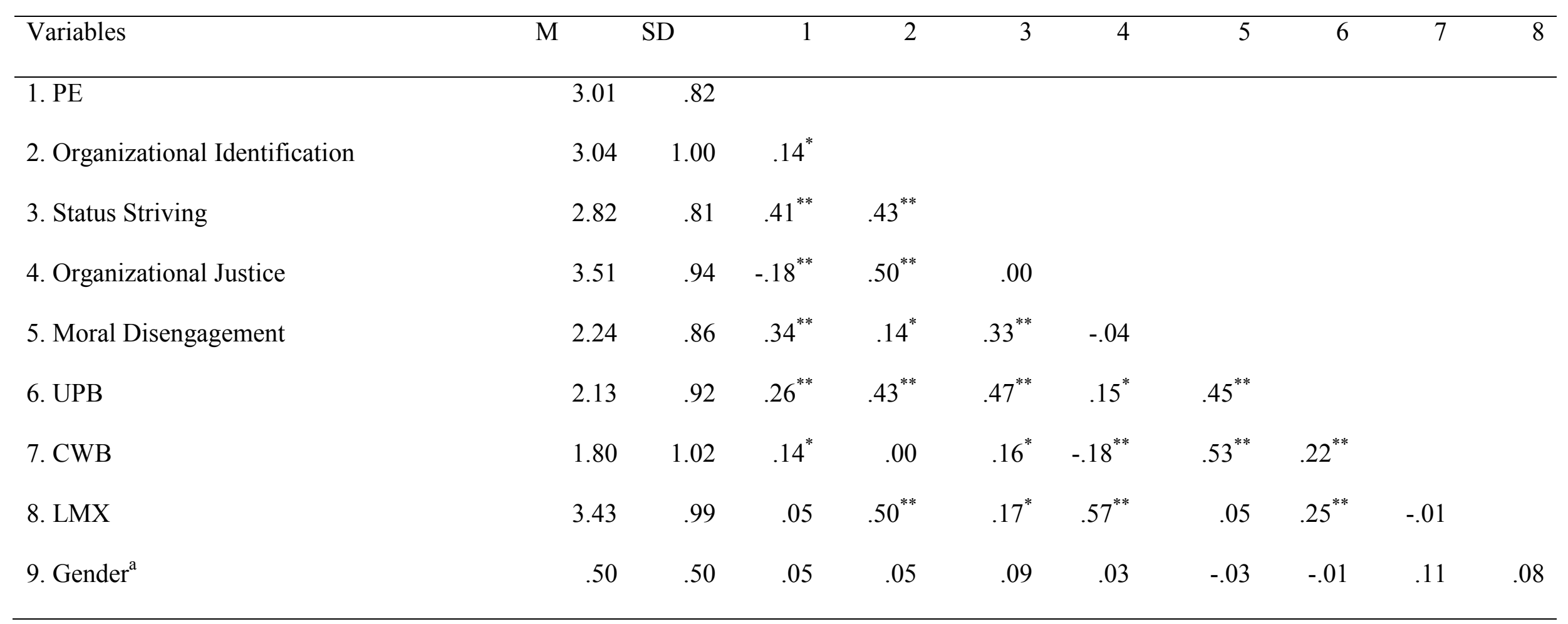

**. Correlation is significant at the 0.01 level (2-tailed).

*. Correlation is significant at the 0.05 level (2-tailed).

a $0=$ Female, $1=$ Male 
Table 5

Results of Moderated Mediation Analysis for UPB, Study 2

Mediators

Outcome Variables

\begin{tabular}{|c|c|c|c|c|c|c|c|c|c|c|}
\hline & \multicolumn{2}{|c|}{ Status Striving (SS) } & \multicolumn{2}{|c|}{$\begin{array}{c}\text { Organizational Justice } \\
\text { (OJ) }\end{array}$} & \multicolumn{2}{|c|}{$\begin{array}{c}\text { Moral } \\
\text { Disengagement (MD) }\end{array}$} & \multicolumn{2}{|c|}{ UPB } & \multicolumn{2}{|c|}{ CWB } \\
\hline & B & $S E$ & $\boldsymbol{B}$ & $S E$ & $B$ & $S E$ & $\boldsymbol{B}$ & $S E$ & $\boldsymbol{B}$ & $S E$ \\
\hline LMX & $.16^{* *}$ & .05 & $.55^{* *}$ & .05 & .07 & .06 & .06 & .06 & .08 & .08 \\
\hline PE & $.42 * *$ & .06 & $-.17 * *$ & .06 & $.37 * *$ & .07 & .06 & .07 & -.08 & .08 \\
\hline SS & & & & & & & $.28 * *$ & .07 & -.04 & .09 \\
\hline OJ & & & & & & & .01 & .07 & $-.28 * *$ & .08 \\
\hline MD & & & & & & & $.33^{* *}$ & .06 & $.66^{* *}$ & .07 \\
\hline PE*OI & & & & & & & .07 & .06 & .07 & .08 \\
\hline$R^{2}$ & $.21^{* *}$ & & $.35^{* *}$ & & $.12 * *$ & & $.41^{* *}$ & & $.37 * *$ & \\
\hline
\end{tabular}

**. Correlation is significant at the 0.01 level (2-tailed). *. Correlation is significant at the 0.05 level (2-tailed).

a $0=$ Female, $1=$ Male 
Table 6

Conditional Indirect Effect of PE on UPB and CWB at +/- 1 Standard Deviation of Organizational Identification

\begin{tabular}{|c|c|c|c|c|}
\hline \multirow[b]{2}{*}{ Organizational Identification } & \multicolumn{2}{|c|}{ UPB } & \multicolumn{2}{|c|}{ CWB } \\
\hline & Estimate (SE) & $95 \%$ CI & Estimate $(\mathrm{SE})^{\mathbf{a}}$ & $95 \%$ CI \\
\hline \multicolumn{5}{|l|}{ Direct Effect } \\
\hline $0 \mathrm{SD}$ OI & $.06(.07)$ & {$[-.08, .20]$} & $-.08(.08)$ & {$[-.24, .08]$} \\
\hline$+1 \mathrm{SD}$ OI & $.13(.10)$ & {$[-.06, .33]$} & $.01(.12)$ & {$[-.24, .22]$} \\
\hline$-1 \mathrm{SD}$ OI & $.12(.04)$ & {$[.04, .21]$} & $-.06(.05)$ & {$[-16, .03]$} \\
\hline $0 \mathrm{SD} O \mathrm{OI}$ & $.12(.03)$ & {$[.06, .19]$} & $-.02(.04)$ & {$[-.08, .06]$} \\
\hline$+1 \mathrm{SD} O \mathrm{OI}$ & $.11(.05)$ & {$[.03, .23]$} & $.03(.05)$ & {$[-.05, .14]$} \\
\hline \multicolumn{5}{|l|}{ Organizational Justice } \\
\hline \multicolumn{5}{|l|}{ Moral Disengagement } \\
\hline$-1 \mathrm{SD}$ OI & $.08(.04)$ & {$[.02, .19]$} & $.24(08)$ & {$[.12, .43]$} \\
\hline $0 \mathrm{SD}$ OI & $.12(.04)$ & {$[.05, .21]$} & $.25(.07)$ & {$[.13, .41]$} \\
\hline$+1 \mathrm{SD}$ OI & $.16(.06)$ & {$[.06, .30]$} & $.25(.09)$ & {$[.11, .46]$} \\
\hline
\end{tabular}


This is the version of the article accepted for publication in Journal of Business Ethics published online by Springer: https://link.springer.com/article/10.1007/s10551-017-3456-z

Accepted version downloaded from SOAS Research Online: http://eprints.soas.ac.uk/23838/

Figure 1

Intention to engage in UPB as a function of PE with low and high organizational identification

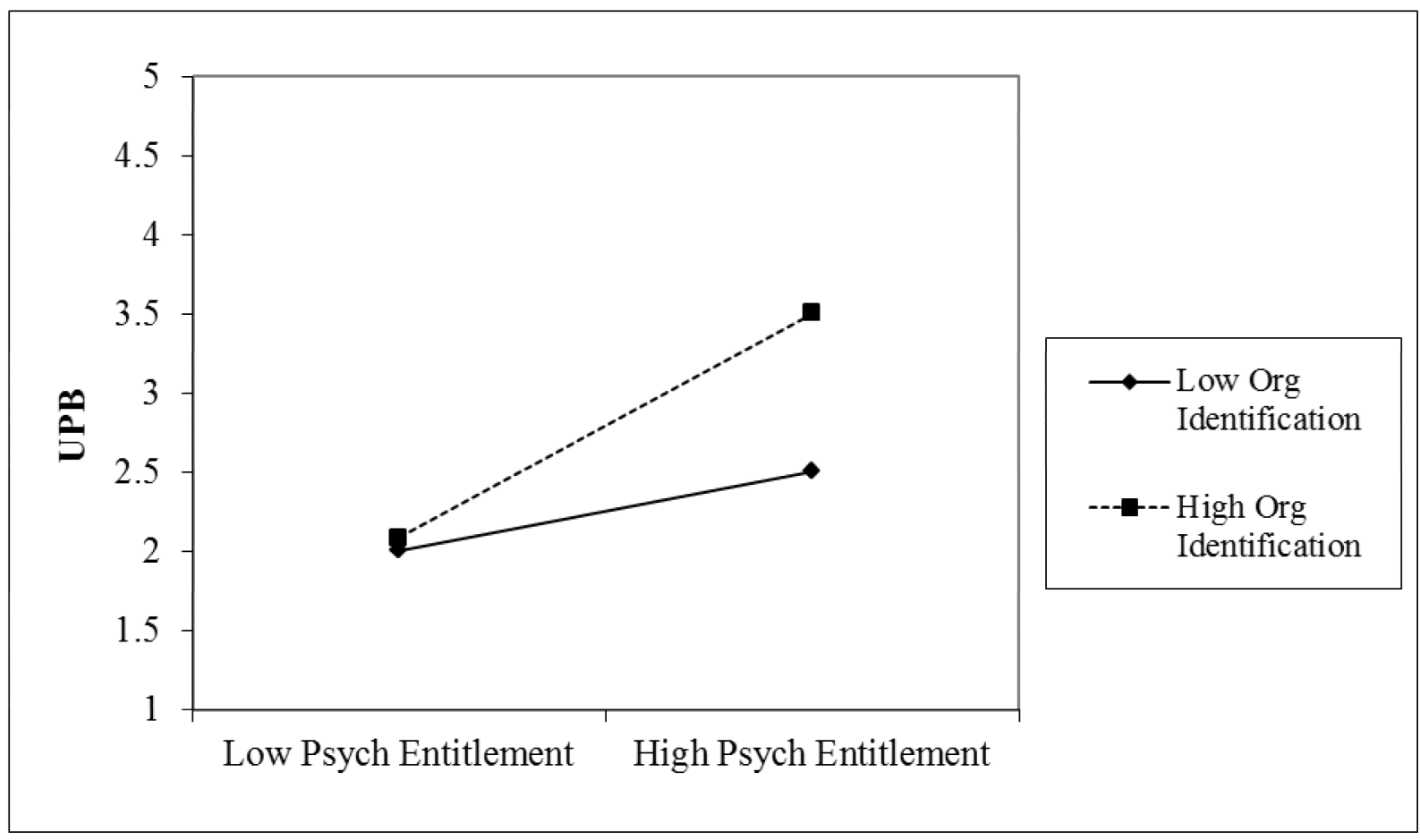


This is the version of the article accepted for publication in Journal of Business Ethics published online by Springer: https://link.springer.com/article/10.1007/s10551-017-3456-z

Accepted version downloaded from SOAS Research Online: http://eprints.soas.ac.uk/23838/

Figure 2

Intention to engage in UPB as a function of moral disengagement with low and high organizational identification

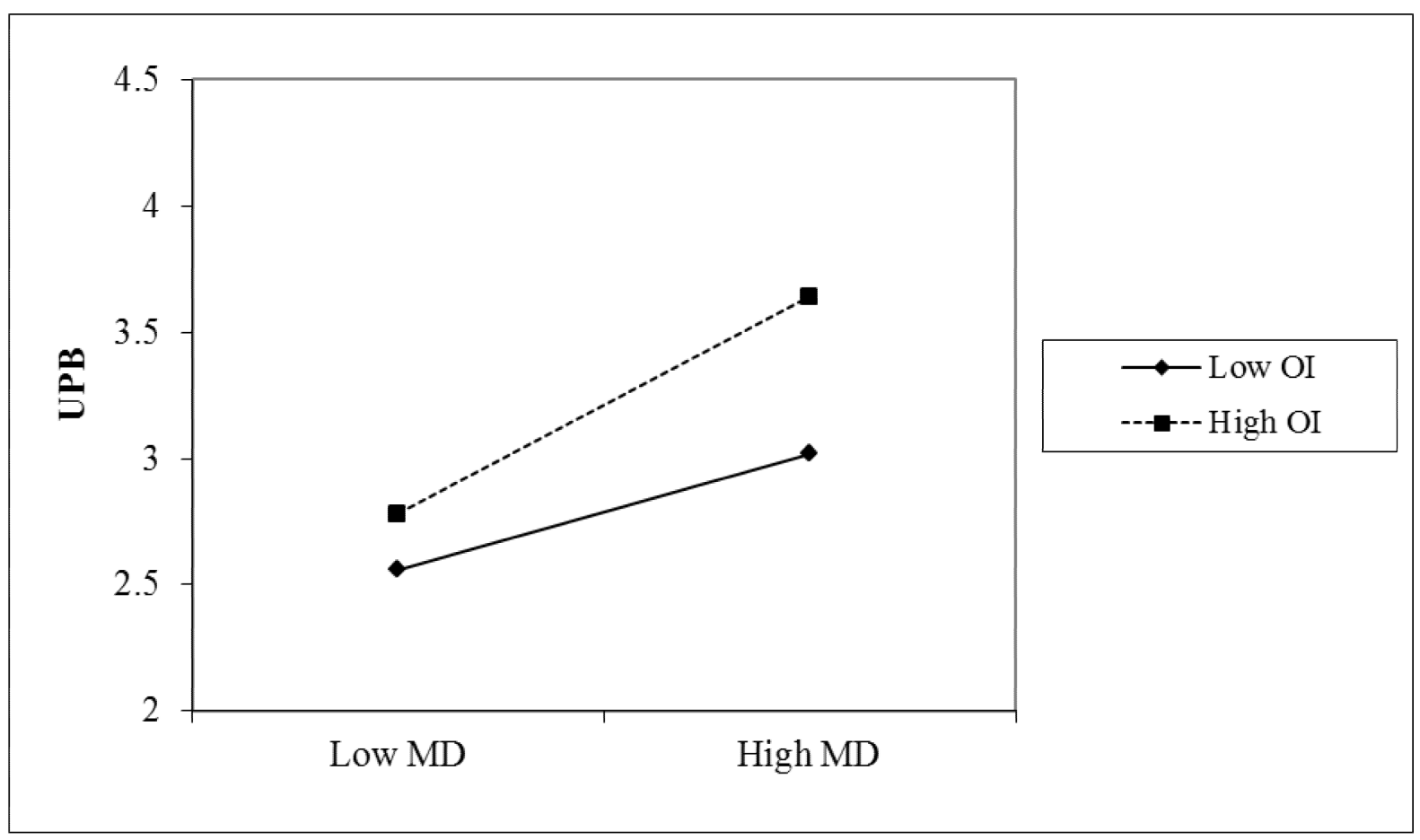

